\title{
ANALISIS STRATEGI PENGEMBANGAN SISTEM INFORMASI PADA PT GUNANUSA ERAMANDIRI DENGAN METODE ENTERPRISE ARCHITECTURE
}

\author{
Roy Kurniawan \\ Information Systems Department, School of Information Systems, BINUS University \\ Jl.KH.Syahdan no.9 Kemanggisan Palmerah Jakarta Indonesia \\ roy_kurniawan@binus.ac.id
}

\begin{abstract}
The purpose of this study was to analyze the needs of the enterprise information system in order to submit a proposed information systems strategy. Research methods used in this research is the analysis of the Enterprise Architecture. The proposed planning is business strategy planning and information technology systems in companies, which can be used within a period of several years. The conclusion from this study is that the proposed planning system can help the company's performance in running business processes, and create a competitive advantage for the company to stay afloat and ahead of the stiff competition in the present or in the future.
\end{abstract}

Keywords: Enterprise Architecture

\begin{abstract}
ABSTRAK
Tujuan penelitian ini adalah menganalisa kebutuhan perusahaan atas sistem informasi untuk mengajukan suatu usulan strategi sistem informasi. Metode penelitian yang digunakan dalam penelitian ini adalah metode analisis Enterprise Architecture. Perencanaan yang diusulkan adalah perencanaan strategi bisnis, sistem dan teknologi informasi pada perusahaan yang bisa digunakan dalam kurun waktu beberapa tahun. Kesimpulan dari penelitian ini adalah perencanaan sistem yang diusulkan ini dapat membantu kinerja perusahaan dalam menjalankan proses bisnis, serta menciptakan keunggulan kompetitif agar perusahaan tetap bertahan dan lebih maju dalam persaingan yang ketat pada masa kini ataupun pada masa yang akan datang.
\end{abstract}

Kata kunci: Enterprise Architecture 


\section{PENDAHULUAN}

PT. Gunanusa Eramandiri merupakan perusahaan industri yang bergerak di bidang farmasi dan kesehatan. Perusahaan ini menawarkan produk yang bertujuan untuk memberikan pelayanan kesehatan. PT. Gunanusa Eramandiri memiliki proses bisnis yang membutuhkan keakuratan di setiap tahap agar aliran data dan informasi berjalan sesuai dengan rencana dan tujuan perusahaan. Seperti yang terjadi pada proses pembelian bahan baku yang terdiri dari proses pemesanan bahan baku, proses penerimaan bahan baku dan proses pengujian bahan baku, sering terjadi kendala sehingga terlambat pada semua proses. Ketelambatan ini terjadi karena pengumpulan data yang belum terintegrasi. Oleh karena itu diperlukan pemecahan masalah dalam strategi dan sistem informasi perusahaan yang bertujuan untuk memaksimalkan proses pembelian bahan baku yang ada agar berjalan semakin baik. Dengan adanya pemecahan masalah, strategi dan sistem informasi tersebut dapat memberikan manfaat yang berguna bagi perusahaan.

Menurut jurnal Anjar Priandoyo (2006), assessment terhadap strategi pengembangan sistem informasi adalah hal yang mutlak dilakukan untuk mendapatkan peningkatan kualitas. Suatu perusahaan dapat meningkatkan pendapatan bila mengetahui bagaimana cara meningkatkan efisiensi proses bisnisnya. Dengan asessment maka perusahaan dapat mengetahui kelemahan yang ada, membandingkannya dengan contoh penerapan di perusahaan lain dan pada akhirnya adalah peningkatan keuntungan perusahaan. Menurut jurnal Masing (2009), dengan penerapan sistem informasi yang tepat, perusahaan akan mendapatkan pengaruh yang positif yaitu pendapatan dan efisiensi proses meningkat dan biaya menurun.

Penelitian ini membahas antara lain: (1) Analisis data, informasi serta teknologi informasi yang ada pada PT. Gunanusa Eramandiri dibatasi pada bagian quality operation manager dan bagian plant logistic manager PT. Gunanusa Eramandiri. (2) Penyusunan rencana strategi bisnis, sistem informasi dan teknologi informasi dibatasi pada bagian quality operation manager dan bagian plant logistic manager PT. Gunanusa Eramandiri.

Tujuan dari penelitian ini adalah: (1) Mengindentifikasi masalah yang berkaitan dengan sistem pada bagian quality operation manager dan bagian plant logistic manager PT. Gunanusa Eramandiri. (2) Menganalisis kebutuhan informasi pada bagian quality operation manager dan bagian plant logistic manager PT. Gunanusa Eramandiri. (3) Menghasilkan usulan strategi sistem informasi bagi PT. Gunanusa Eramandiri yang dapat dipakai sebagai pedoman dalam pengembangan sistem informasi.

Manfaat dari penelitian ini adalah: (1) Data dan informasi yang dimiliki perusahaan mampu dikelola dengan baik. (2) Mempermudah perusahaan dalam mengoptimalkan peran strategi SI/TI organisasi guna meningkatkan nilai bisnis pada perusahaan. (3) Mencapai visi dan misi PT. Gunanusa Eramandiri dengan lebih terarah karena didukung dengan perencanaan strategi sistem dan teknologi informasi.

\section{METODE}

Metodologi yang digunakan di dalam penulisan ini adalah studi kepustakaan, metode survei dan metode analisis dan pengamatan. Studi kepustakaan adalah studi terhadap beberapa sumbersumber terkait dengan penulisan agar analisis dan perancangan sesuai dengan metode-metode yang ada dan dapat dipahami. Studi kepustakaan juga melakukan pemeriksaan terhadap hasil penelitian terdahulu, buku teks, jurnal serta makalah ilmiah yang di mana pernah mengangkat masalah, topik 
atau isu yang yang akan dibuat. Metode survei adalah melakukan survei dan wawancara dengan beberapa pihak manajemen PT. Gunanusa Eramandiri dengan maksud untuk memahami tujuan yang ingin dicapai, serta proses bisnis yang dijalankan diberbagai divisi di PT. Gunanusa Eramandiri.

\section{Metode Analisis dan Pengamatan}

Metodologi yang digunakan dalam penulisan ini adalah melakukan pengamatan proses bisnis dan operasional dan menggunakan Enterprise Architecture yang telah dikemukakan Bernard, S.A (2005).
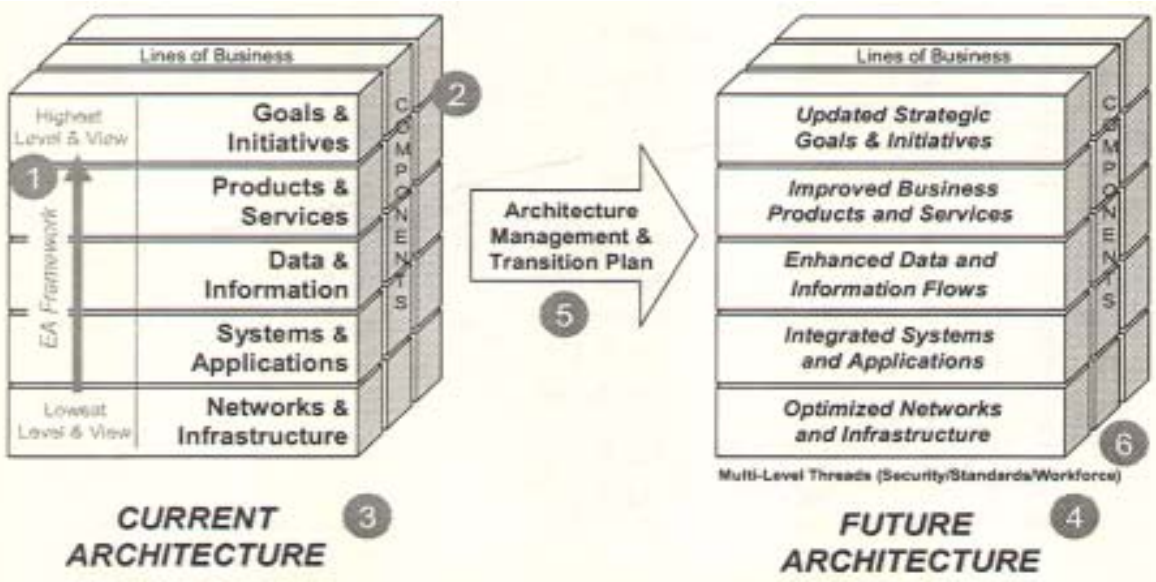

Gambar 1 Enterprise Architecture Documentation

Proses analisa dilakukan dengan memetakan arsitektur saat ini yaitu Sasaran Strategis dan Inisiatif, Produk dan Layanan Jasa, Data dan Informasi, Aplikasi Sistem dan Rancangan Teknologi dan Infrastruktur. Selanjutnya adalah melakukan perencanaan transisi dan mengelola arsitektur yang ada sehingga menghasilkan arsitektur di masa mendatang.

\section{HASIL DAN PEMBAHASAN}

\section{Enterprise Architecture Management Plan}

Enterprise Architecture Management Plan bertujuan untuk merencanakan transisi dan masa depan sistem dan teknologi informasi pada PT. Gunanusa Eramandiri.

\section{Enterprise Architecture Program Management}

Enterprise Architecture Program yang dilakukan pada PT. Gunanusa Eramandiri bertujuan untuk melakukan suatu usulan perubahan atau perbaikan pada proses bisnis, struktur organisasi dan mengusulkan penggunaan beberapa teknologi informasi yang dapat lebih efektif dalam membantu kegiatan beberapa divisi. 


\section{Governance and Principles}

Enterprise Architecture mempunyai kebijakan dalam pembuatannya, kebijakan pemerintah menjadi sumber utama dalam keberhasilan program Enterprise Architecture ini. PT. Gunanusa Eramandiri mempunyai kebijakan dari Badan Pemeriksa Obat dan Makanan Republik Indonesia (BPOM), yaitu melakukan regulasi dan standarisasi pada bahan baku produk yang akan dipasarkan.

\section{Support for Strategy and Business}

Dukungan program Enterprise Architecture dalam hal strategi dan bisnis pada PT. Gunanusa Eramandiri adalah untuk membantu mencapai strategi yang ada dalam visi dan misi dari PT. Gunanusa Eramandiri dengan menggunakan dukungan-dukungan dari usulan teknologi informasi. Usulan teknologi informasi ini diharapkan dapat membantu dalam efektifitas yang adapada proses pembeliaan bahan baku untuk mencapai sasaran strategi.

\section{Enterprise Architecture Roles and Responsibilities}

Enterprise Architecture Roles and Responsibilites ini membahas tentang peranan dan tanggung jawab dalam mengimplementasikan metode Enterprise Architecture pada PT. Gunanusa Eramandiri.

Tabel 1 Enterprise Architecture Roles and Responsibility

\begin{tabular}{lll}
\hline $\begin{array}{l}\text { Enterprise } \\
\text { Architecture Team } \\
\text { Position }\end{array}$ & Enterprise Architecture Team Role & $\begin{array}{l}\text { Enterprise Architecture } \\
\text { Responsibility }\end{array}$ \\
\hline TO Director & Pimpinan Eksekutif & $\begin{array}{l}\text { Melakukan pengontrolan dan } \\
\text { pengawasan dalam penerapan EA }\end{array}$ \\
$\begin{array}{l}\text { Database } \\
\text { Administator }\end{array}$ & $\begin{array}{l}\text { Melakukan pekerjaan yang berkaitan } \\
\text { dengan database dan administrasi } \\
\text { security }\end{array}$ & $\begin{array}{l}\text { Bertanggung jawab atas atas } \\
\text { aspek-aspek dalam lingkungan } \\
\text { database }\end{array}$ \\
Web Developer & $\begin{array}{l}\text { Melakukan pekerjaan yang berkaitan } \\
\text { dengan web dan design web, }\end{array}$ & $\begin{array}{l}\text { Bertanggung jawab atas web yang } \\
\text { telah di rancang. }\end{array}$ \\
\hline
\end{tabular}

Sumber : Hasil Pengolahan Data, 2014

\section{Enterprise Architecture Program Budget}

Dengan adanya peremajaan fasilitas pada PT. Gunanusa Eramandiri maka diperlukan pula perencanaan biaya yang akan di butuhkan untuk membeli hardware dan software. Berikut ini adalah rincian perencanaan biaya yang akan dipakai untuk pengadaan hardware dan software. 
Tabel 2 Enterprise Architecture Program Budget

\begin{tabular}{|c|c|c|c|c|}
\hline Jenis & Spesifikasi & Jumlah & Harga & Total \\
\hline \multirow[t]{3}{*}{ Hardware } & $\begin{array}{l}\text { Desktop :HP Desktop 110-010l } \\
\text { Processors : intel Pentium Core } 2 \text { Duo } \\
\text { Memory RAM : 4GB (2x2GB) DDR3 PC-12800 } \\
\text { HardiskDrive : 1TB, Serial ATA 7200RPM } \\
\text { VGA : Intel }{ }^{\circledR} \text { HD Graphics } \\
\text { Monitor : SAMSUNG Monitor LCD SyncMaster } \\
\text { S19A10N }\end{array}$ & 7 & $4,300,000$ & 30.100 .000 \\
\hline & $\begin{array}{l}\text { Server : HP ProLiant ML310eG8 v2 - 241(Database) } \\
\text { Processors : Intel Xeon Processor E3-1240 v2 (8M } \\
\text { Cache,3.40 GHz) } \\
\text { Motherboard Intel server motherboard, Intel® S3420 } \\
\text { Server Chipset } \\
\text { Memory8 GB PC3-12800E DDR3 ECC } \\
\text { Disk Storage 2TB Serial ATA-II/300 } \\
\text { Monitor SAMSUNG Monitor LCD SyncMaster } \\
\text { S19A10N }\end{array}$ & 1 & 17.500 .000 & 17.500 .000 \\
\hline & $\begin{array}{l}\text { Printer : HP Officejet 6500ALL-IN-ONE } \\
\text { Modem: Linksys AM300 } \\
\text { Routers : CISCO Wireless N VPN Router } \\
\text { Switch : CISCO SF90D-16-AS } \\
\text { Kabel LAN }\end{array}$ & $\begin{array}{c}3 \\
1 \\
1 \\
1 \\
305 \mathrm{M}\end{array}$ & $\begin{array}{c}1.990 .000 \\
400.00 \\
699.000 \\
1.063 .000 \\
1.765 .000\end{array}$ & $\begin{array}{c}5.970 .000 \\
400.000 \\
699.000 \\
1.063 .000 \\
17.650 .000\end{array}$ \\
\hline $\begin{array}{l}\text { Operating } \\
\text { system }\end{array}$ & $\begin{array}{l}\text { MICROSOFT Windows } 7 \text { Home Premium } \\
\text { Windows server } 2008\end{array}$ & $\begin{array}{l}7 \\
1\end{array}$ & $\begin{array}{c}1.773 .200 \\
10.894 .000\end{array}$ & $\begin{array}{l}12.412 .400 \\
10.894 .400\end{array}$ \\
\hline & Grand Total & & & 96.688 .000 \\
\hline
\end{tabular}

Sumber : Hasil Analisis dan Pengolahan Data, 2014

\section{Enterprise Architecture Current Architecture Summary}

\section{Strategic Goal and Initiatives}

Dalam rangka mencapai visi dan misi perusahaan maka setiap karyawan ikut mendukung dengan mengikuti pelatihan dalam rangka untuk meningkatkan kualitas sumber daya manusia yang akan menggunakan teknologi tersebut.

\section{Business services and information flows}

Pelayanan proses bisnis dapat ditingkatkan dalam hal menganalisis proses bisnis dan mengoptimalkan alur informasi. 
Tabel 3 Alur Informasi PT. Gunanusa Eramandiri

\begin{tabular}{|c|c|c|c|}
\hline Line Of Business & Key Process & Information Flow & $\begin{array}{l}\text { Supporting } \\
\text { Component }\end{array}$ \\
\hline Pemesanan Bahan Baku & Website e-scm & $\begin{array}{l}\text { Perusahaanmengirimpurchase order dan } \\
\text { supplier menerima purchase order }\end{array}$ & Warehouse Supervisor \\
\hline $\begin{array}{l}\text { Penerimaan Bahan Baku } \\
\text { Pengujian bahan Baku }\end{array}$ & $\begin{array}{l}\text { Website e-scm } \\
\text { Website e-scm }\end{array}$ & $\begin{array}{l}\text { Pembuatan dan dokumentasi data bahan baku } \\
\text { Pembuatan dan dokumentasi data pengujian } \\
\text { bahan baku }\end{array}$ & $\begin{array}{l}\text { Warehouse Foreman } \\
\text { Quality Control } \\
\text { Section Head }\end{array}$ \\
\hline
\end{tabular}

Sumber : Hasil Analisis dan Pengolahan Data, 2014

\section{System and Applications}

Sistem dan aplikasi yang ada pada PT. Gunanusa Eramandiri berupa aplikasi-aplikasi standar perusahaan seperti Microsoft Office.

\section{Technology Infrastructure}

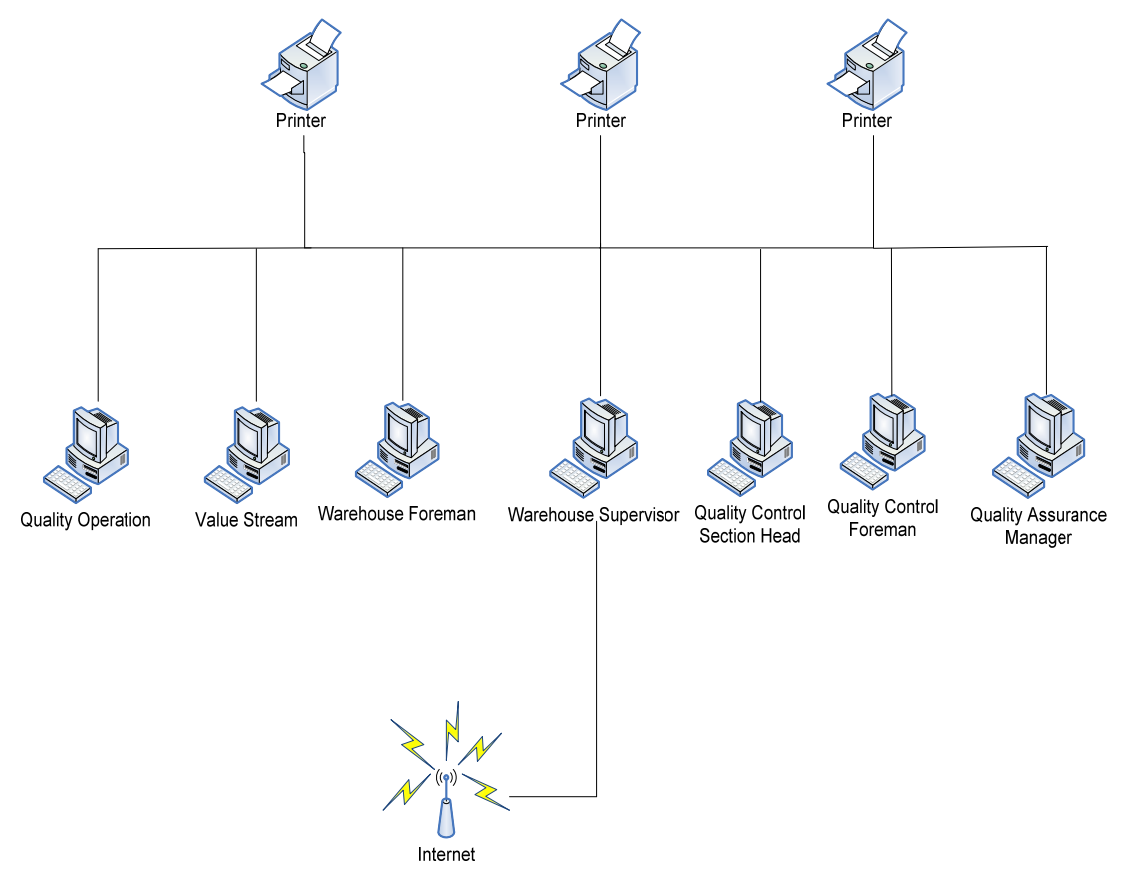

Gambar 2 Infrastruktur IT PT. Gunanusa Eramandiri Sumber : Analisis dan Pengolahan Data, 2014

\section{IT Security}

Keamanan IT yang diterapkan di PT. Gunanusa Eramandiri masih kurang memenuhi standar. Dalam perencanaan yang diusulkan untuk soal pengamanan perusahaan diantara lain hak akses data dan komputer yang digunakan.

\section{Enterprise Architecture Standards}

PT. Gunanusa Eramandiri memiliki standar sistem yang kurang memadai. Semua komputer karyawan memiliki standar yang sama dan penyimpanan dokumen-dokumen hanya disimpan di dalam satu ruangan. 


\section{Workforce Requirements}

Dalam meningkatkan kualitas sumber daya manusia perlu diadakan pelatihan-pelatihan yang berguna untuk menyeimbangkan peningkatan teknologi dengan kinerja pegawai yang ada di perusahaan.

\section{Enterprise Architecture Future Architecture Summary}

\section{Future Operation Scenarios}

PT. Gunanusa Eramandiri sudah mempunyai proses bisnis yang baik. untuk meningkatkan efektifitas dan efisiensi di masa depan perlu ada penambahan pada beberapa proses seperti dengan mengubah sistem menjadi terintegrasi dan penyimpanan data dengan database.

\section{Planning Assumptions}

Asumsi perencanaan akan merubah alur proses bisnis yang ada sehingga saling terintegrasi. Dengan adanya pengembangan dan penambahan teknologi bertujuan untuk mempermudah jalannya proses bisnis yang ada. Meniadakan beberapa proses manual juga mengurangi dampak pengurangan kertas yang digunakan. Serta diperlukan penambahan database guna menunjang penyimpanan data yang ada di perusahaan. Selanjutnya, meningkatkan pelayanan, pengetahuan dan kemampuan dengan melakukan pengembangan SDM maka akan diadakan pelatihan untuk meningkatkan kualitas SDM yang ada di PT. Gunanusa Eramandiri.

\section{Update Current and Future Views}

Goals and initiative; dalam melakukan pencapaian strategi-strategi PT. Gunanusa Eramandiri akan membutuhkan suatu tujuan dan target baru yang dapat membantu perusahaan. Dalam pencapaian ini digunakan analisis SWOT (Strength, Weakness, Opportunities, Threat). Dalam kasus ini dominan kekuatan dan peluang dari PT. Gunanusa Eramandiri yang dapat menjadi acuan dalam pengembangan perancangan system baru. Product and Service; adanya beberapa perubahan dari proses bisnis yang dilakukkan pada PT. Gunanusa Eramandiri dengan meningkatkan penggunaan teknologi informasi akan membantu dalam mencapai tujuan yang ingin dicapai. Pembangunan website nantinya akan meningkatkan efektifitas dan efisiensi dari proses bisnis yang berjalan di perusahaan.

Data and Information; adanya perubahan dalam level ini karena system penyimpanan data yang dimiliki PT.Gunanusa Eramandiri kurang efektif karena pengerjaannya masih belum terintegrasi. Oleh karena itu diusulkan sistem yang akan mengintegrasikan pada proses pembelian bahan baku. System and Application; terdapat beberapa bagian ataupun perubahan pada sistem yang berjalan pada PT. Gunanusa Eramandiri yaitu dengan dilakukannya perubahan sistem yang belum terintegrasi menjadi terintegrasi sehingga dapat mempermudah tiap bagian pada pembelian bahan baku untuk mengetahui proses yang berjalan. Network and Infrastructure; pada bagian ini terjadi penambahan hardware dan software yang harus digunakan oleh perusahaan dalam jangka waktu beberapa tahun ke depan.

\section{Enterprise Architecture Glossary and References}

Current View; Enterprise Architecture artefak yang mewakili komponen Enterprise Architecture atau proses yang sedang berjalan pada perusahaan. Future View; Enterprise Architecture artefak yang mewakili komponen Enterprise Architecture atau proses yang akan diusulkan dan belum ada dalam perusahaan. 


\section{Current Class Diagram}

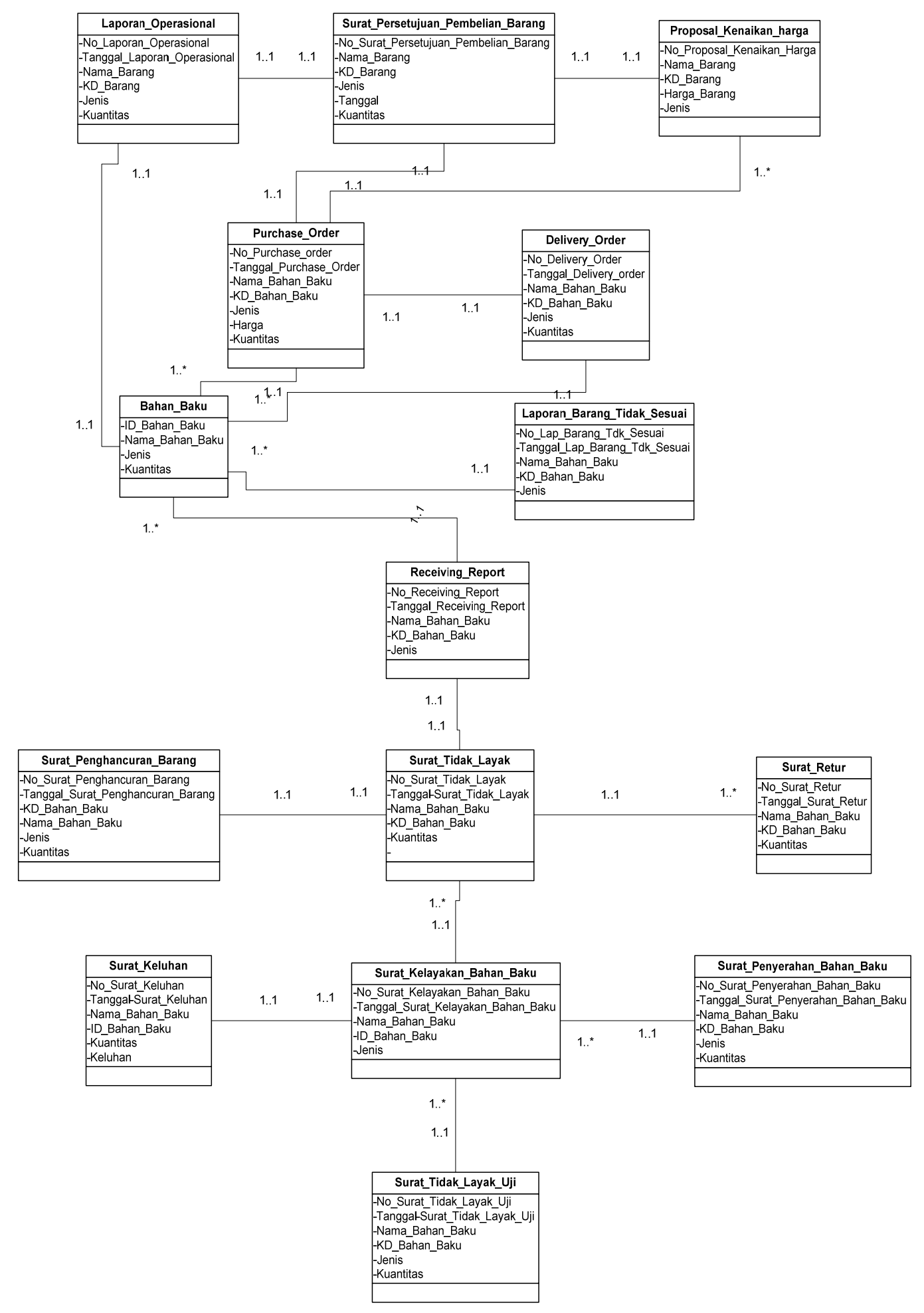

Gambar 3 Current Class Diagram 


\section{Future Class Diagram}

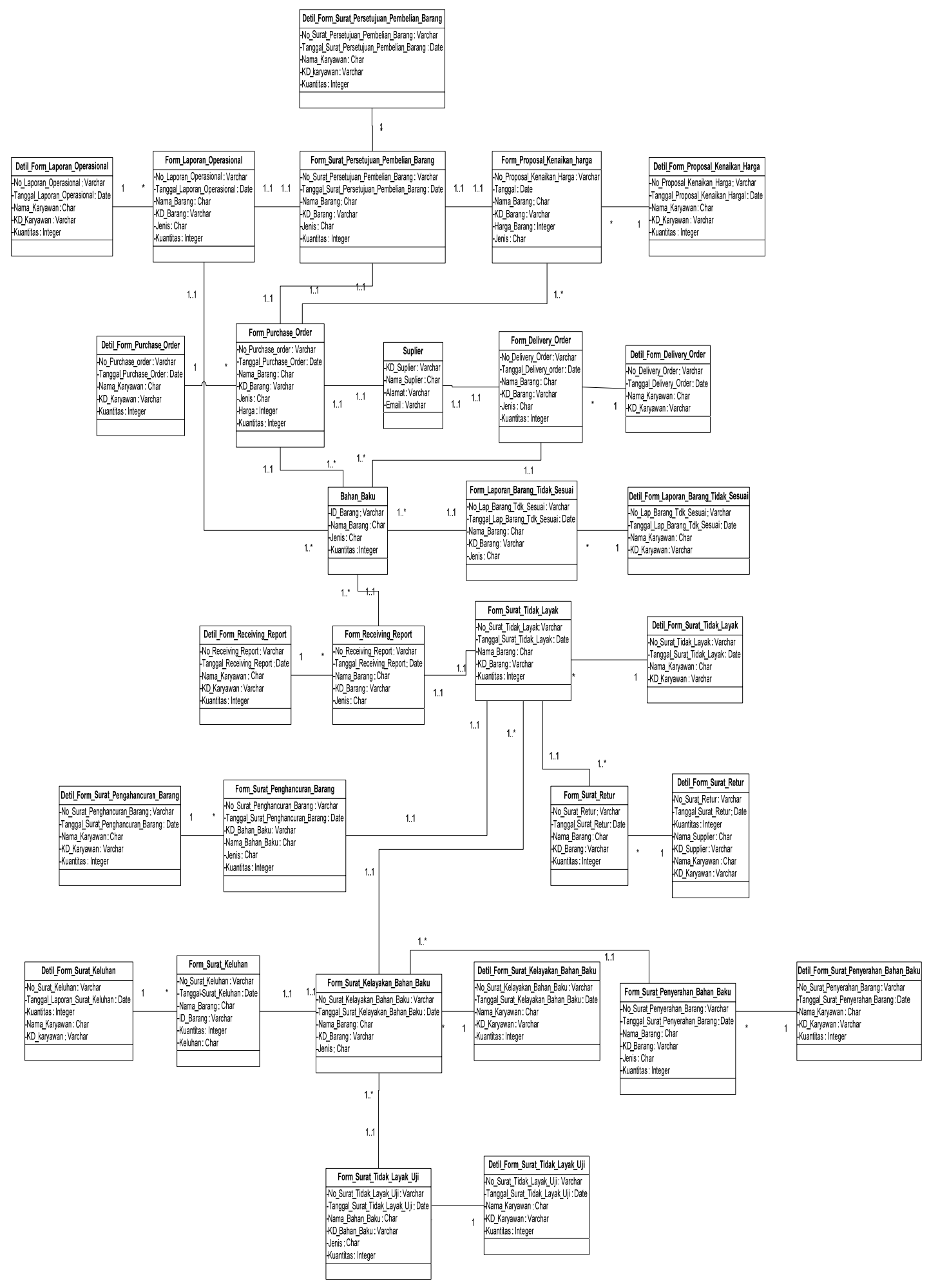

Gambar 4 Future Class Diagram 


\section{SIMPULAN}

Berdasarkan dari analisis hasil penelitian yang telah dilakukan pada arsitektur sistem dan teknologi yang sedang berjalan maupun rancangan arsitektur sistem dan teknologi informasi masa depan, sistem yang ada saat ini belum terintegrasi sehingga proses yang berjalan pada pembelian bahan baku menjadi kurang efektif dan efisien. Penggunaan kertas untuk dokumen berdampak kurang baik karena bisa berakibat kehilangan atau rusak. Penggunaan teknologi informasi belum optimal dalam membantu proses bisnis pada PT. Gunanusa Eramandiri.

Berdasarkan dari simpulan, PT. Gunanusa Eramandiri dapat melakukan optimalisasi sumber daya manusia agar mendukung pengembangan teknologi informasi dalam proses bisnis perusahaan. Pengembangan teknologi informasi seperti website, penyimpanan data dalam bentuk digital sehingga meningkatkan efektivitas dan efisiensi proses bisnis. PT. Gunanusa Eramandiri perlu mengadakan evaluasi secara berkala untuk melakukan pengembangan yang lebih lanjut

\section{DAFTAR PUSTAKA}

Bernard, S. A. (2005). An Introduction to Enterprise Architecture (2 ${ }^{\text {nd }}$ Edition). Blooming, IN: Author House.

Masing, E. (2009). Tehnical Support: Improving Performance and Reducing Costs With. IT Risk Management. Risk Management, 56(8).

Priandoyo, A. (2006). Vulnerability Assessment untuk Meningkatkan Kesadaran Pentingnya Keamanan Informasi. Jurnal Sistem Informasi, 1(2). 